\title{
The relative importance of decomposition and transport mechanisms in accounting for soil organic carbon profiles
}

\author{
B. Guenet ${ }^{1,2}$, T. Eglin ${ }^{1}$, N. Vasilyeva ${ }^{3}$, P. Peylin ${ }^{1}$, P. Ciais ${ }^{1}$, and C. Chenu ${ }^{3}$ \\ ${ }^{1}$ Laboratoire des Sciences du Climat et de l'Environnement, UMR8212, CEA-CNRS-UVSQ, 91191 Gif-sur-Yvette, France \\ ${ }^{2}$ Department of Biology, University of Antwerpen, Universiteitsplein 1, 2610, Wilrijk, Belgium \\ ${ }^{3}$ AgroParisTech, UPMC-CNRS-AgroParisTech UMR Bioemco7618, 78850 Thiverval-Grignon, France
}

Correspondence to: B. Guenet (bertrand.guenet@ua.ac.be)

Received: 5 September 2012 - Published in Biogeosciences Discuss.: 15 October 2012

Revised: 8 March 2013 - Accepted: 14 March 2013 - Published: 10 April 2013

\begin{abstract}
Soil is the major terrestrial reservoir of carbon and a substantial part of this carbon is stored in deep layers, typically deeper than $50 \mathrm{~cm}$ below the surface. Several studies underlined the quantitative importance of this deep soil organic carbon (SOC) pool and models are needed to better understand this stock and its evolution under climate and land-uses changes. In this study, we tested and compared three simple theoretical models of vertical transport for SOC against SOC profiles measurements from a long-term bare fallow experiment carried out by the Central-Chernozem State Natural Biosphere Reserve in the Kursk Region of Russia. The transport schemes tested are diffusion, advection and both diffusion and advection. They are coupled to three different formulations of soil carbon decomposition kinetics. The first formulation is a first order kinetics widely used in global SOC decomposition models; the second one, socalled "priming" model, links SOC decomposition rate to the amount of fresh organic matter, representing the substrate interactions. The last one is also a first order kinetics, but SOC is split into two pools. Field data are from a set of three bare fallow plots where soil received no input during the past 20 , 26 and $58 \mathrm{yr}$, respectively. Parameters of the models were optimised using a Bayesian method. The best results are obtained when SOC decomposition is assumed to be controlled by fresh organic matter (i.e., the priming model). In comparison to the first-order kinetic model, the priming model reduces the overestimation in the deep layers. We also observed that the transport scheme that improved the fit with the data depended on the soil carbon mineralisation formulation chosen. When soil carbon decomposition was modelled to depend on the fresh organic matter amount, the transport
\end{abstract}

mechanism which improved best the fit to the SOC profile data was the model representing both advection and diffusion. Interestingly, the older the bare fallow is, the lesser the need for diffusion is, suggesting that stabilised carbon may not be transported within the profile by the same mechanisms than more labile carbon.

\section{Introduction}

Soils are the major reservoir of terrestrial organic carbon (C) representing more than twice the amount of $\mathrm{C}$ stored in the atmosphere and three times the amount of $\mathrm{C}$ stored in terrestrial vegetation (Schimel, 1995; Schlesinger, 1990; MEA, 2005). In spite of the importance of the stock, the dynamics of soil C is not deeply understood (Sugden et al., 2004). Soil scientists have mainly focused on the surface horizons (Lueken et al., 1962; Sparling et al., 1982; Wu et al., 1993), which were considered to be the only depth of the soil which can emit $\mathrm{CO}_{2}$ to the atmosphere in significant amounts. However, recent studies have shown that the amount of $\mathrm{C}$ stored in the deep layers (below $30 \mathrm{~cm}$ ) could represent between 30 and $63 \%$ of the total amount of soil C (Batjes, 1996; Jobbagy and Jackson, 2000; Tarnocai et al., 2009). Consequently, increasing attention has been paid to deep soil $\mathrm{C}$ and in particular to its dynamics (Fontaine et al., 2007; Salomé et al., 2010; Rumpel et al., 2010; Sanaullah et al., 2010).

Transport mechanisms of soil $\mathrm{C}$ into deep layers is still not well understood. The models applied at site-level generally represent both vertical advection and diffusion (Elzein and Balesdent, 1995; Bruun et al., 2007; Braakhekke et al., 
2011), but models also exist with only advection (Feng et al., 1999; Dörr and Münnich, 1989; Jenkinson and Coleman, 2008) or only diffusion (O'Brien and Stout, 1978; Wynn et al., 2005). To our knowledge, no formal and comprehensive comparison of the three transport mechanisms combined to different representations of decomposition has been performed, even if Bruun et al. (2007) suggested that the representation of both advection and diffusion mechanisms improved their model for a sandy soil. However, they compared a model with both advection and diffusion to an advectiononly model, but they do not compare these models with a diffusion-only model.

The Soil Organic Matter (SOM) decomposition mechanisms proposed as equations that can be encapsulated in models are also very diverse (for review see, Manzoni and Porporato, 2009; Wutzler and Reichstein, 2008). Within all these approaches, the most used formulation is the first order kinetics as in CENTURY (Parton et al., 1988) or in RothC (Coleman and Jenkinson, 1996). In this formulation, the decay of each SOM pool is proportional to the pool's size, thereby considering that there are no interactions between two decomposing pools.

In particular, within the fourth Assessment Report (AR4) of the Intergovernmental Panel on Climate Change (IPCC), the climate-carbon models used during the Coupled Carbon Cycle Climate Model Intercomparison Project ( $\left.\mathrm{C}^{4} \mathrm{MIP}\right)$ represented the SOM decomposition with first order kinetics (Friedlingstein et al., 2006). This approach is now criticised (Fontaine and Barot, 2005; Wutzler and Reichstein, 2008), in particular, for its incapacity to represent the relationship existing between Fresh Organic Matter (FOM) inputs (e.g., roots exudates, litter, etc.) and the mineralisation of the SOM. This interaction seems to be a major mechanism of SOM stabilisation in the deep soil layers (Fontaine et al., 2007) even if it could be soil dependent (Salomé et al., 2010). However, here again, to our knowledge no clear comparison between first order kinetics and any of the alternative decomposition formulations linking FOM input to SOM mineralisation has been done.

To study how FOM may possibly interact with SOM mineralisation, experimental sites such as long-term bare fallow soils are interesting experiments. Instead of the complexity of real soils where FOM is permanently added and depends on ecosystem properties, in a bare fallow, the input of FOM has been stopped. Consequently, the relationship between FOM input and SOM mineralisation is switched-off in the bare fallow, whereas it remains switched on in the control plots. In our case, we used bare fallow soils sampled at different years including periods where FOM was assumed to be still available, because it had not yet decomposed, and periods where FOM stock was assumed to be close to zero (Barré et al., 2010).

In this study, we developed a suite of conceptual models to compare the three main transport schemes (advection only $T_{\mathrm{A}}$; diffusion only $T_{\mathrm{D}}$, both together $T_{\mathrm{AD}}$ ) proposed in the literature using measurement of soil $\mathrm{C}$ profiles obtained in a long-term bare fallow and a control plot near Kursk in Russia. We also aimed to cross the three transport schemes with the different formulations used to describe SOM mineralisation: a first order kinetics without relationship between FOM input and SOM mineralisation and a formulation inspired from Wutzler and Reichstein (2008) where the relationship between FOM input and SOM mineralisation is represented. Moreover, we used a three pools model with decomposition based on first order kinetics with both advection and diffusion to better understand how increasing the number of parameters may improve the fit with the data. We first optimised the parameters of each of the seven possible models, using the observed soil carbon profiles and a statistical optimisation method (least square minimization). We then compared the model outputs with measurements from all soil carbon profiles from the bare fallow.

\section{Materials and methods}

\subsection{The Kursk long-term field experiment data}

\subsubsection{Site and soil plots description}

Soils were sampled at the long-term field experiment the Central-Chernozem State Natural Biosphere Reserve named after V. V. Alekhin in the Kursk Region of Russia. The climatic zone is a forest steppe temperate, moderately cold with a mean annual precipitation of $587 \mathrm{~mm}$ and a mean annual air temperature of $5.4{ }^{\circ} \mathrm{C}$ (Central-Chernozem State Natural Biosphere Reserve, 1947-1997). The soil is a Haplic Chernozem defined as a silty loam Haplic Luvisol following the FAO classification. Two long-term plots were sampled within the site located in the Streletskyi section of the reserve at $51^{\circ} \mathrm{N}, 36^{\circ} \mathrm{E}$, about $18 \mathrm{~km}$ south of the city of Kursk (Vinogradov, 1984).

The first plot is a long-term bare fallow soil where no fresh input entered the soils since 1947. The soil was weeded manually and tilled every year by horse traction at a depth corresponding to $17-18 \mathrm{~cm}$ until the middle of the $1970 \mathrm{~s}$ and then using a machine at a depth of $22-24 \mathrm{~cm}$. Before the start of the experiment, the soil was under a natural steppe that had been under hay-harvest and pasture for at least the last four centuries. The second plot is geographically close to the first one (about $50 \mathrm{~m}$ ). It is the same natural steppe that has been absolutely reserved since the establishment of the Reserve in 1935 (Afanasyeva, 1966). It is a natural steppe since 1935 and was used previously for pasture. Dominant plant species are meadow bromegrass (Bromus riparius Rehm.), wild oats (Stipa pennata L.), narrow-leaved meadow grass (Poa angustifolia L.), intermediate wheatgrass (Elytrigia intermedia (Host) Nevski), meadowsweet rose (Filipendula vulgaris Moench), and green strawberry (Fragaria viridis 
Duch.). This soil is considered as a control (undisturbed) plot for the bare fallow experiment.

\subsubsection{Soil sampling and carbon measurements}

Soils were sampled at the bare fallow plot in 1967, 1973 and 2005 at depths of every $10 \mathrm{~cm}$ down to $150 \mathrm{~cm}$. The soil of the steppe was sampled in 2006 at depths of every $10 \mathrm{~cm}$ down to $150 \mathrm{~cm}$. Soils were sampled five times in the steppe, in the bare fallow in 1967 and 2005 and three times in 1973. The corresponding profiles are hereafter called $20 \mathrm{YBF}, 26 \mathrm{YBF}$ and 58YBF for the bare fallow soil sampled in 1967, 1973 and 2005, respectively (i.e., after 20, 26 and $58 \mathrm{yr}$ of bare fallow) and $\mathrm{S}$ for the steppe. $\mathrm{C}$ contents obtained by the Tyurin method in 1967 and 1973 are corrected by a multiplicative factor 1.13, determined particularly for this soil to match dry combustion method and, thus, avoid any underestimation of the C content (Vasilyeva et al., 2013). In years 2005 and 2006, soil C was measured by dry combustion (Vario Elementar, Analysensysteme, Hanau, Germany).

The bulk density of the soils was first measured for each layer until $120 \mathrm{~cm}$ depth in 1959 , and this measurement was repeated in 2002 for the bare fallow and for the steppe plots. To take into account the difference in bulk density between the samples, the $\mathrm{C}$ stocks are expressed in $\mathrm{kg} \mathrm{C} \mathrm{m}^{-2}$ as follows:

$\mathrm{C}_{\text {stock }}=\mathrm{TOC} \times \mathrm{BD} \times h$

with TOC being the total organic carbon content of the layer considered, expressed in $\mathrm{kg} \mathrm{C} \mathrm{kg}^{-1}$ soil, BD the bulk density expressed in $\mathrm{kg} \mathrm{soil} \mathrm{m}^{-3}$ and $h$ the layer height expressed in $\mathrm{m}$. Since bulk densities are available only until $120 \mathrm{~cm}$, the soil profiles in $\mathrm{kg} \mathrm{C} \mathrm{m}^{-2}$ are calculated only until $120 \mathrm{~cm}$ depth. The bulk densities measured in 1959 are used for the soil layer sampled in 1967 and in 1973, whereas the bulk densities measured in 2002 are used for the soil layers sampled in 2005 and in 2006. The chronosequence used in this study is interesting because it follows the decrease of the FOM stock from an equilibrium to another. Indeed, Barré et al. (2010) showed that FOM stock are generally close to zero after $40 \mathrm{yr}$ of bare fallow. Thus, FOM stock is assumed to be high and at the equilibrium for the steppe and close to zero, but also at the equilibrium for the $58 \mathrm{YBF}$. The $20 \mathrm{YBF}$ and the $26 \mathrm{YBF}$ profiles being intermediate situations.

\subsection{Soil carbon decomposition models}

The models used in this study split the total OM in two pools, the FOM and the SOM for each soil layer (Fig. 1). Input to the FOM pool comes from plant litter and the distribution of this input within the profile is assumed to depend upon depth from the surface $(z)$ according to a negative exponential function, in order to represent the decreased injection of FOM from root mortality with increasing $z$. This is given by the equation:

$I(z)=\frac{I \times \exp (-\mu \times z)}{\sum \exp (-\mu \times z)}$

where $I(z)$ defines the input of FOM at depth $z, I$ is a scalar corresponding to the total input of carbon. We used $I=3.4 \mathrm{~kg} \mathrm{C} \mathrm{m}^{-2} \mathrm{yr}^{-1}$ which is the mean of the $\mathrm{C}$ input over the period 1954-1961 for the steppe considered in this study (Afanasyeva, 1966). $\mu$ is a parameter describing the exponential of FOM input from root mortality (or exudates) in the vertical profile.

Plant litter production is considered as constant and does not depend on climatic forcing. FOM mineralisation is assumed to be governed by first order kinetics, being proportional to the FOM pool, as given by:

$$
\frac{\partial \mathrm{FOM}_{\mathrm{dec}}}{\partial t}=-k_{\mathrm{FOM}} \times \mathrm{FOM}
$$

where FOM is the FOM carbon pool and $k_{\mathrm{FOM}}$ is a scalar defining its decomposition rate. A fraction of decomposed FOM is humified $(e)$ and another is respired as $\mathrm{CO}_{2}(1-e)$ (Fig 1).

Humified FOM $=e \times \frac{\partial \mathrm{FOM}_{\mathrm{dec}}}{\partial t}$

Respired FOM $=(1-e) \times \frac{\partial \mathrm{FOM}_{\mathrm{dec}}}{\partial t}$

For other fluxes, we test 7 different model formulations, resulting from the combination of three formulations to describe SOM mineralisation (MIN), with three formulations to describe the vertical transport of carbon $(T)$.

\subsubsection{Formulation MIN1}

The mineralisation of SOM is assumed to follow first order kinetics, depending only on the SOM amount, as given by:

$\frac{\partial \mathrm{SOM}_{\mathrm{dec}}}{\partial t}=-k_{\mathrm{SOM}} \times \mathrm{SOM} \times t f$

where SOM is the SOM carbon pool, $k_{\mathrm{SOM}}$ its decomposition rate, and $t f$ a parameter accelerating the mineralisation due to tillage in the bare fallow soils.

A fraction of decomposed SOM returns to the FOM assuming that a part of the SOM decomposition products is as labile as FOM $(e)$ and another is respired as $\mathrm{CO}_{2}(1-e)$ (Fig. 1).

Humified SOM $=e \times \frac{\partial \mathrm{SOM}_{\mathrm{dec}}}{\partial t}$

Respired SOM $=(1-e) \times \frac{\partial \mathrm{SOM}_{\mathrm{dec}}}{\partial t}$ 


\subsubsection{Formulation MIN2}

The mineralisation of SOM depends on decomposer activity and, therefore, is sensitive to FOM availability, according to:

$\frac{\partial \mathrm{SOM}_{\mathrm{dec}}}{\partial t}=-k_{\mathrm{SOM}}^{\prime} \times \mathrm{SOM} \times(1-\exp (-c \times \mathrm{FOM})) \times \mathrm{tf}$

where $k_{\mathrm{SOM}}^{\prime}$ is a SOM decomposition rate, $c$ a parameter controlling the importance of the FOM carbon pool in the SOM mineralisation, and $t f$ a parameter accelerating the mineralisation due to tillage when necessary. Equation (9) is inspired from Wutzler and Reichstein (2008) who used $\frac{\partial \mathrm{SOM}_{\mathrm{dec}}}{\partial t}=$ $-k_{\mathrm{SOM}}^{\prime} \times \mathrm{SOM} \times(1-\exp (-c \times \mathrm{MB}))$, but unlike in their study, we do not explicitly represent microbial biomass, the MB term in Wutzler and Reichstein (2008) and rather we use a direct relationship between SOM mineralisation and FOM stock. Thus, Eq. (9) assumes that microbial biomass is always in equilibrium with FOM. A fraction of decomposed SOM returns to the FOM assuming that a part of the SOM decomposition products is as labile as FOM $(e)$ and another is respired as $\mathrm{CO}_{2}(1-e)$ following Eqs. (7) and (8).

\subsubsection{Formulation MIN3}

Here, the mineralisation of SOM follows Eq. (6), but SOM is split into two pools with different mineralisation rates: the slow SOM and the passive SOM. The C-FOM mineralised is distributed into these pools according to:

Slow $\mathrm{SOM}=f \times$ Humified FOM

Passive SOM $=(1-f) \times$ Humified FOM

where $f$ is the fraction of humified FOM which goes to the slow SOM pool.

A fraction of decomposed passive SOM returns to the FOM assuming that a part of the passive SOM decomposition products is as labile as FOM and another is respired as $\mathrm{CO}_{2}$ following Eqs. (7) and (8). For the slow pool, a part is respired as $\mathrm{CO}_{2}$ and the rest is distributed into the FOM assuming that a part of the slow SOM decomposition products is as labile as FOM C mineralised and the rest is going to the passive pools.

The three different formulations of $\mathrm{C}$ transport are based on an advection equation $\left(T_{\mathrm{A}}\right)$ or on Fick's law of diffusion $\left(T_{\mathrm{D}}\right)$ or on both transport mechanisms as defined by Elzein and Balesdent (1995) $\left(T_{\mathrm{AD}}\right)$.

\subsubsection{Formulation $T_{\mathrm{A}}$}

Advection is defined by:

$F_{\mathrm{A}}=A \times \mathrm{C}$

where $F_{\mathrm{A}}$ is the flux of $\mathrm{C}$ transported downwards by advection, $A$ the advection rate $\left(\mathrm{mm} \mathrm{yr}^{-1}\right)$.

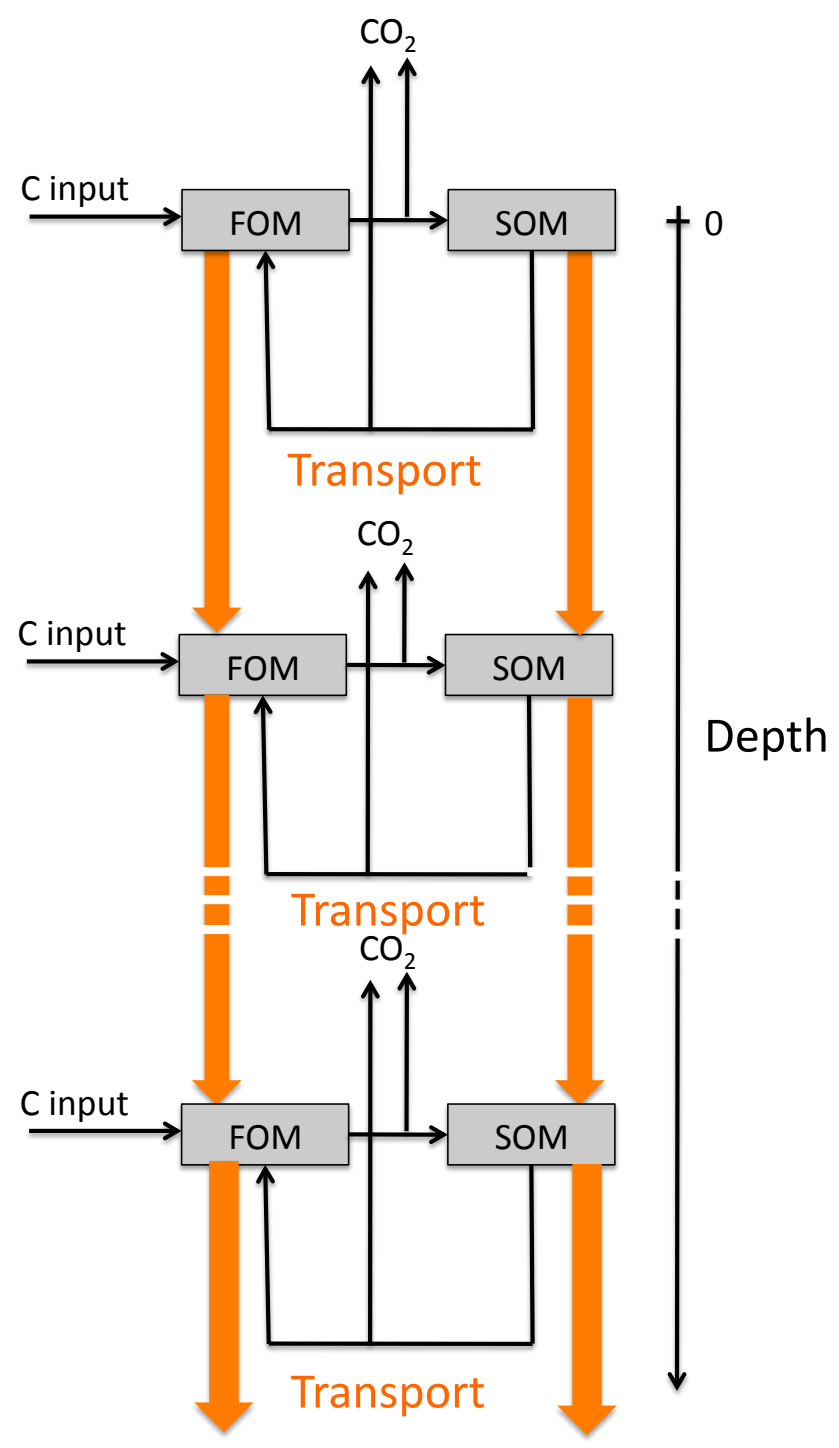

Fig. 1. Schematic representation of the fluxes and the pool in the model.

\subsubsection{Formulation $T_{\mathrm{D}}$}

The Fick's law is defined by:

$F_{\mathrm{D}}=-D \times \frac{\partial^{2} C}{\partial^{2} z}$

where $F_{\mathrm{D}}$ is the flux of $\mathrm{C}$ transported downwards by diffusion, $-D$ the diffusion coefficient $\left(\mathrm{cm}^{2} \mathrm{yr}^{-1}\right)$ and $C$ the amount of carbon in the pool subject to transport (FOM or SOM).

\subsubsection{Formulation $T_{\mathrm{AD}}$}

Finally, advection and diffusion are represented following the scheme of Elzein and Balesdent (1995)

$F_{\mathrm{AD}}=F_{\mathrm{A}}+F_{\mathrm{D}}$ 


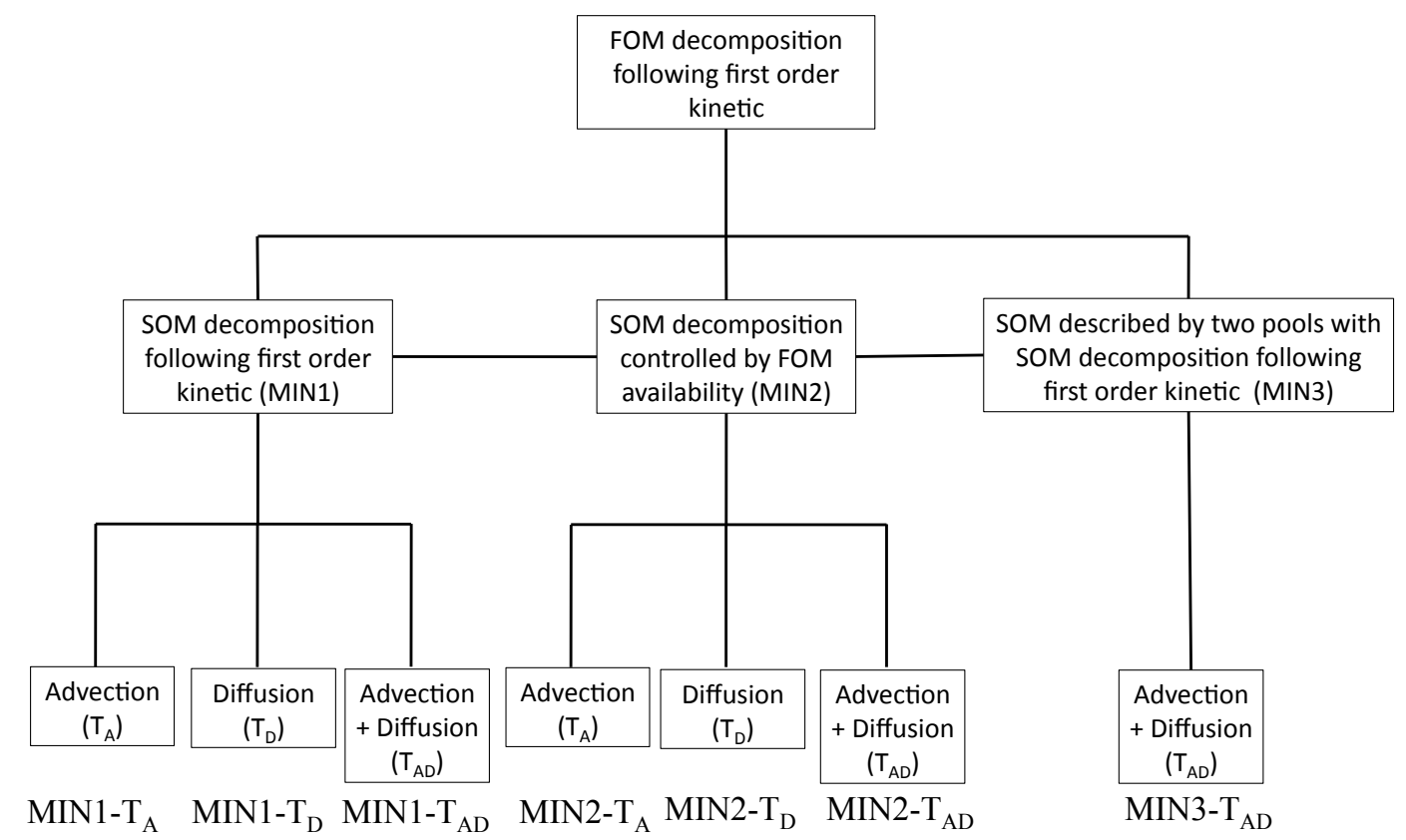

Fig. 2. Presentation of the seven formulations used in this study.

$F_{\mathrm{AD}}=A \times C-D \times \frac{\partial^{2} C}{\partial^{2} z}$

where $F_{\mathrm{AD}}$ is the flux of $\mathrm{C}$ transported downwards by advection and diffusion, $A$ the advection rate, $-D$ the diffusion coefficient and $C$ the amount of carbon in the pool subject to transport. We finally build the seven different models by forming pair of (MIN, T) formulations as illustrated by Fig. 2. Thus, the FOM and SOM pools dynamics correspond to:

$$
\begin{gathered}
\frac{\partial \mathrm{FOM}}{\partial t \partial z}=I+\frac{\partial F_{X}}{\partial z}+e \times \frac{\partial \mathrm{SOM}_{\mathrm{dec}}}{\partial t}-\frac{\partial \mathrm{FOM}_{\mathrm{dec}}}{\partial t} \\
\frac{\partial \mathrm{SOM}}{\partial t \partial z}=\frac{\partial F_{X}}{\partial z}+e \times \frac{\partial \mathrm{FOM}_{\mathrm{dec}}}{\partial t}-\frac{\partial \mathrm{SOM}_{\mathrm{dec}}}{\partial t}
\end{gathered}
$$

All the models were developed using R 2.11.1 and run at a yearly time step. The models run from the ground $(0 \mathrm{~cm})$ until $200 \mathrm{~cm}$ and the vertical resolution is $5 \mathrm{~mm}$ for each layer. To compare with the data, $\mathrm{C}$ stocks are then summed each 20 layers to obtain $10 \mathrm{~cm}$ layers. Moreover only the layers until $120 \mathrm{~cm}$ are used since the data could be converted in $\mathrm{kg} \mathrm{C} \mathrm{m}^{-2}$ only until $120 \mathrm{~cm}$. The equations were solved using the deSolve library (Soetaert et al., 2010). This library solves a system of ordinary differential equations resulting from one dimensional partial differential equations that have been converted to ordinary differential equations by numerical differencing. We run the models with the steppe condition (i.e., with input of FOM) during $2000 \mathrm{yr}$ to reach the equilibrium. The steppe was assumed to be at the equilibrium and we used the C stocks obtained after the $2000 \mathrm{yr}$ run for the steppe. Then we run the model for $58 \mathrm{yr}$ without FOM input to reproduce the $58 \mathrm{YBF}$ plots condition. From this run, we extracted the data after 20 and $26 \mathrm{yr}$ to reproduce the $20 \mathrm{YBF}$ and $26 \mathrm{YBF}$ plots condition, respectively.

\subsection{Parameter optimisation}

The 10 parameters used for each simulation are listed in Table 1. Eight of them are optimised for each model using a Bayesian inversion method with priors (see Tarantola, 1987) against the entire dataset (48 data points, i.e., 12 for each profile), with a statistical approach based on a Bayesian framework (Tarantola, 1987). Our approach is based on Santaren et al. (2007). The optimal parameter set corresponds to the minimum of the cost function

$J(x)=\frac{1}{2}\left[(\boldsymbol{y}-H(x))^{t} R^{-1}(\boldsymbol{y}-H(x))+\left(\boldsymbol{x}-x_{b}\right)^{t} P_{b}^{-1}\left(\boldsymbol{x}-x_{b}\right)\right]$

and contains both the mismatch between modelled and observed fluxes and the mismatch between prior and optimised parameters. $\boldsymbol{x}$ is the vector of unknown parameters, $x_{b}$ the prior parameters, $H(x)$ the model outputs and $\boldsymbol{y}$ the vector of observations. $P_{b}$ describes the prior parameter error variances/covariances, while $R$ contains the prior data error variances/covariances.

An efficient gradient-based iterative algorithm, called LBFGS-B (Zhu et al., 1995) was used to minimise the cost function. This algorithm prescribes a range of values for each parameter. At each iteration, the gradient of the cost function $J(x)$ is computed, with respect to all the parameters. The L-BFGS-B algorithm does not provide uncertainties or 
Table 1. Model parameters summary for the model MIN1- $T_{\mathrm{A}}, \mathrm{MIN} 1-T_{\mathrm{D}}, \mathrm{MIN} 1-T_{\mathrm{AD}}, \mathrm{MIN} 2-T_{\mathrm{A}}, \mathrm{MIN} 2-T_{\mathrm{D}}, \mathrm{MIN} 2-T_{\mathrm{AD}}$.

\begin{tabular}{|c|c|c|c|c|c|c|c|c|c|}
\hline \multirow{2}{*}{$\begin{array}{l}\text { Model } \\
\text { parameter }\end{array}$} & \multirow[t]{2}{*}{ Meaning } & \multirow{2}{*}{$\begin{array}{l}\text { Optimized } \\
\text { parameter }\end{array}$} & \multirow{2}{*}{$\begin{array}{l}\text { Prior } \\
\text { range }\end{array}$} & \multicolumn{6}{|c|}{ Posterior modes \pm variance (prior modes) } \\
\hline & & & & $\mathrm{MIN} 1-T_{\mathrm{A}}$ & $\mathrm{MIN} 1-T_{\mathrm{D}}$ & MIN1- $T_{\mathrm{AD}}$ & $\mathrm{MIN} 2-T_{\mathrm{A}}$ & $\mathrm{MIN} 2-T_{\mathrm{AD}}$ & $\mathrm{MIN} 2-T_{\mathrm{AD}}$ \\
\hline$I$ & $\begin{array}{l}\text { Input of FOM ( } \mathrm{kg} \mathrm{C} \\
\left.\mathrm{m}^{-2} \mathrm{yr}^{-1}\right)\end{array}$ & NO & N.A & \multicolumn{6}{|c|}{3.4} \\
\hline$\mu$ & $\begin{array}{l}\text { Exponential rate pa- } \\
\text { rameter of FOM in- } \\
\text { put from root mortal- } \\
\text { ity }\end{array}$ & YES & $0.2-2$ & $\begin{array}{l}1.382 \pm 0.015 \\
(0.357)\end{array}$ & $\begin{array}{l}1.0 \pm 0.714 \\
(1.0)\end{array}$ & $\begin{array}{l}1.466 \pm 0.004 \\
(0.228)\end{array}$ & $\begin{array}{l}1.521 \pm 0.004 \\
(1.742)\end{array}$ & $\begin{array}{l}0.954 \pm 0.11 \\
(0.357)\end{array}$ & $\begin{array}{l}1.459 \pm 0.002 \\
(0.369)\end{array}$ \\
\hline$k_{\mathrm{FOM}}$ & $\begin{array}{l}\text { Decomposition rate } \\
\text { of FOM }\end{array}$ & YES & $0.2-10$ & $\begin{array}{l}0.467 \pm 0.163 \\
(0.467)\end{array}$ & $\begin{array}{l}0.833 \pm 0.192 \\
(0.833)\end{array}$ & $\begin{array}{l}0.200 \pm 0.059 \\
(0.221)\end{array}$ & $\begin{array}{l}0.313 \pm 0.139 \\
(0.313)\end{array}$ & $\begin{array}{l}0.467 \pm 0.163 \\
(0.467)\end{array}$ & $\begin{array}{l}0.375 \pm 0.15 \\
(0.375)\end{array}$ \\
\hline$r$ & $\begin{array}{l}\text { Respiration rate of } \\
\text { FOM }\end{array}$ & NO & N.A & \multicolumn{6}{|c|}{0.4} \\
\hline$k_{\text {SOM }}$ & $\begin{array}{l}\text { Decomposition rate } \\
\text { of SOM }\end{array}$ & YES & $2 \mathrm{e}^{-3}-0.2$ & $\begin{array}{l}1.11 \mathrm{e}^{-2} \pm 0.1 \\
\mathrm{e}^{-4}\left(2.50 \mathrm{e}^{-2}\right)\end{array}$ & $\begin{array}{l}5.46 \mathrm{e}^{-3} \pm 0.17 \\
\mathrm{e}^{-3}\left(3.33 \mathrm{e}^{-2}\right)\end{array}$ & $\begin{array}{l}3.36 \mathrm{e}^{-3} \pm 0.45 \\
\mathrm{e}^{-3}\left(3.52 \mathrm{e}^{-3}\right)\end{array}$ & $\begin{array}{l}6.74 \mathrm{e}^{-3} \pm 0.12 \\
\mathrm{e}^{-3}\left(4.15^{-3}\right)\end{array}$ & $\begin{array}{l}1.04 \mathrm{e}^{-2} \pm 0.04 \\
\left(2.50 \mathrm{e}^{-2}\right)\end{array}$ & $\begin{array}{l}1.02 \mathrm{e}^{-2} \pm 0.01 \\
\left(3.65 \mathrm{e}^{-2}\right)\end{array}$ \\
\hline$e$ & Humification rate & YES & $0.1-0.9$ & $\begin{array}{l}0.726 \pm 0.132 \\
(0.726)\end{array}$ & $0.5 \pm 0.06(0.5)$ & $\begin{array}{l}0.323 \pm 0.027 \\
(0.324)\end{array}$ & $\begin{array}{l}0.579 \pm 0.084 \\
(0.579)\end{array}$ & $\begin{array}{l}0.726 \pm 0.132 \\
(0.726)\end{array}$ & $\begin{array}{l}0.669 \pm 0.110 \\
(0.669)\end{array}$ \\
\hline$A$ & $\begin{array}{l}\text { Advection coeffi- } \\
\text { cient }\left(\mathrm{mm} \mathrm{yr}^{-1}\right)\end{array}$ & YES & $0.01-1$ & $\begin{array}{l}0.282 \pm 0.001 \\
(0.298)\end{array}$ & N.A & $\begin{array}{l}0.365 \pm 0.335 \\
(0.366)\end{array}$ & $\begin{array}{l}0.361 \pm 0.326 \\
(0.361)\end{array}$ & N.A & $\begin{array}{l}0.578 \pm 0.31 \\
(0.388)\end{array}$ \\
\hline$D$ & $\begin{array}{l}\text { Diffusion coefficient } \\
\left(\mathrm{cm}^{2} \mathrm{yr}^{-1}\right)\end{array}$ & YES & $1-100$ & N.A & $\begin{array}{l}66.61 \pm 62.3 \\
(50.0)\end{array}$ & $\begin{array}{l}13.63 \pm 4.65 \\
(13.63)\end{array}$ & N.A & $\begin{array}{l}36.32 \pm 22.07 \\
(55.74)\end{array}$ & $\begin{array}{l}14.86 \pm 5.53 \\
(14.86)\end{array}$ \\
\hline$C$ & $\begin{array}{l}\text { Influence of the FOM } \\
\text { carbon pool in the } \\
\text { SOM mineralisation } \\
\text { (priming parameter) }\end{array}$ & YES & $0.1-160$ & N.A & N.A & N.A & $\begin{array}{l}64.91 \pm 1046.31 \\
(64.69)\end{array}$ & $\begin{array}{l}47.57 \pm 20.31 \\
(12.93)\end{array}$ & $\begin{array}{l}90.0 \pm 1959.5 \\
(88.5)\end{array}$ \\
\hline$t f$ & $\begin{array}{l}\text { Acceleration of SOM } \\
\text { mineralisation due to } \\
\text { tillage }\end{array}$ & YES & $1-2.5$ & $\begin{array}{l}1.97 \pm 0.97 \\
(1.97)\end{array}$ & $1.5 \pm 0.56(1.5)$ & $\begin{array}{l}1.02 \pm 0.26 \\
(1.02)\end{array}$ & $\begin{array}{l}2.23 \pm 1.25 \\
(2.23)\end{array}$ & $\begin{array}{l}1.97 \pm 0.96 \\
(1.97)\end{array}$ & $\begin{array}{l}1.01 \pm 0.27 \\
(1.01)\end{array}$ \\
\hline
\end{tabular}

error correlations between optimised parameters, but, when the $J(x)$ is minimised, it calculates the posterior error covariance matrix on the parameters $P_{a}$ from the prior error covariance matrices and the Jacobian of the model at the minimum of the cost function, using the linearity assumption (Tarantola, 1987). Absolute values of the error correlations close to 1 imply that the observations do not provide independent information to differentiate a couple of parameters.

The optimisation assumes that the errors associated to the model parameters and the observations can be described with Gaussian Probability Distribution Function (PDF). Assuming Gaussian PDF, this approach is sensitive to potential local minima. We, therefore, performed 20 optimisations starting from different prior parameter values randomly distributed in their allowed range of variation. We then selected the case that provides the lowest cost function. With this approach, we are much less sensitive to potential local minima. It makes use of prior information on the parameters, minimising an objective function that measures the distance between modelled and observed carbon vertical profiles and between prior and optimised parameter values (using a least squares approach).

The optimised parameters for the models using MIN1 and MIN2 (Table 1) are the SOM decomposition rate $\left(k_{\text {som }}\right)$, the FOM decomposition rate $\left(k_{\text {fom }}\right)$, the exponential rate parameter of FOM input from root mortality in the vertical profile $(\mu)$, the fraction of SOM mineralised recycled in FOM $(e)$, Fick's coefficient in models using $T_{\mathrm{A}}$ or $T_{\mathrm{AD}}(A)$, the advection rate in models using $T_{\mathrm{D}}$ of $T_{\mathrm{AD}}(D)$, the parameter controlling the FOM dependency of the SOM mineralisation in models using MIN2 (c), and the tillage factor to increase mineralisation $(t f)$. Prior estimates for each parameter are given on Table 1. We used such ranges to define priors because they are close to parameters already published (Baisden et al., 2002; Bruun et al., 2007; Braakhekke et al., 2011). However, since the $c$ parameter has never been estimated before, we considered the prior as non-informative and we set a very large prior error $(50 \%)$. For the model using MIN3 the optimised parameters are presented in Table 2. They are the slow SOM decomposition rate $\left(k_{\text {slow }}\right)$, the passive SOM decomposition rate $\left(k_{\text {passive }}\right)$, the FOM decomposition rate $\left(k_{\mathrm{fom}}\right)$, the exponential rate parameter of FOM input from root mortality in the vertical profile $(\mu)$, the fraction of SOM mineralised recycled in the other pools $(e)$, the fraction of FOM mineralised distributed into the slow SOM pool $\left(f_{\mathrm{FS}}\right)$, the fraction of the slow SOM pool mineralised not respired and recycled in the FOM pool $\left(f_{\mathrm{SF}}\right)$ the Fick's coefficient $(D)$, the advection rate $(A)$.

As for the variance of the model-data residuals, note that with our formalism it should include both the measurement error and the model error. Given that the error on the measurements could be estimated from the existence of several replicates for each profile, we choose the measured standard deviation as error on the observations. At its minimum, $J(x)$ should be close to the half of the number of observations (reduced chi-square of one). Note finally that all errors (on the parameters and the observations) are assumed to be uncorrelated.

A compaction of the bare fallow soil is observed on the site, leading to $10 \mathrm{~cm}$ difference between the deepest studied 
Table 2. Model parameters summary for the model MIN3- $T_{\mathrm{AD}}$.

\begin{tabular}{lllll}
\hline $\begin{array}{l}\text { Model } \\
\text { parameter }\end{array}$ & Meaning & $\begin{array}{l}\text { Optimised } \\
\text { parameter }\end{array}$ & $\begin{array}{l}\text { Prior } \\
\text { range }\end{array}$ & $\begin{array}{l}\text { Posterior modes } \pm \text { variance } \\
\text { (prior modes) }\end{array}$ \\
\hline$I$ & Input of FOM $\left(\mathrm{kg} \mathrm{C} \mathrm{m}^{-2} \mathrm{yr}^{-1}\right)$ & NO & N.A & 3.4 \\
$\mu$ & Exponential rate parameter of FOM input from root mortality & YES & $0.2-2$ & $1.68 \pm 0.02(0.86)$ \\
$k_{\text {FOM }}$ & Decomposition rate of FOM & YES & $0.2-10$ & $0.246 \pm 0.137(0.102)$ \\
$r$ & Respiration rate of FOM & NO & N.A & 0.4 \\
$k_{\text {Slow SOM }}$ & Decomposition rate of slow SOM pool & YES & $2 \mathrm{e}^{-3}-0.2$ & $8.7 \mathrm{e}^{-3} \pm 8.6 \mathrm{e}^{-3}\left(8.34 \mathrm{e}^{-5}\right)$ \\
$k_{\text {Passive SOM }}$ & Decomposition rate of passive SOM pool & YES & $3.3 \mathrm{e}^{-4}-1$ & $1.7 \mathrm{e}^{-3} \pm 0.6 \mathrm{e}^{-3}\left(2.53 \mathrm{e}^{-4}\right)$ \\
$r$ & Fraction of SOM C respired & YES & $0.1-0.9$ & $0.742 \pm 0.017(0.725)$ \\
$A$ & Advection coefficient (mm yr $\left.{ }^{-1}\right)$ & YES & $0.01-1$ & $0.686 \pm 0.402(0.818)$ \\
$D$ & Diffusion coefficient $\left(\mathrm{cm}^{2} \mathrm{yr}^{-1}\right)$ & YES & $1-100$ & $18.11 \pm 1.22(57.83)$ \\
$f_{\text {FOM } \rightarrow \text { Slow }}$ & Fraction of humified FOM that goes to the slow SOM pool & YES & $0.1-0.9$ & $0.347 \pm 0.030(0.377)$ \\
$F_{\text {Slow } \rightarrow \text { FOM }}$ & Fraction of decomposed SOM from the slow pool that goes to & YES & $0.1-0.9$ & $0.415 \pm 0.043(0.459)$ \\
& the FOM pool & & & $2.5 \pm 0.16(2.1)$ \\
\hline$f$ & Acceleration of SOM mineralisation due to tillage & YES & $1-2.5$ & 2.5 \\
\hline
\end{tabular}

* Assuming that a part of the decomposition products from Slow SOM pools are as labile as FOM.

horizon of the control and the one of the bare fallow. To take into account graphically the compaction effect on soil depth, we defined the point at $0 \mathrm{~m}$ depth as the floor of the steppe and then the soil layers were assumed to be linearly compacted through time since 1947 to reproduce the observed final difference of $10 \mathrm{~cm}$ depth between the two bottom horizons. The compaction observed on site and its effects on transport are taken into account through the use of the bulk density in the stocks calculation in the dataset. The compaction effects are implicitly represented in the model as the optimisation was performed with the stocks expressed in $\mathrm{kg} \mathrm{C} \mathrm{m}^{-2}$.

\subsection{Comparison of model results with data}

C stock measured and modelled for each soil layer are compared using statistical indicators developed first by Kobayashi and Salam (2000) and then improved by Gauch et al. (2003). These statistical indicators are the Mean Squared Deviation (MSD), the Squared Bias (SB), the Non-Unity slope (NU) and the Lack of Correlation (LC).

$\operatorname{MSD}=\frac{\Sigma(m-o)^{2}}{n}$

with $o$ the observed values, $m$ the C stock calculated by the model and $n$ the number of observations.

The MSD is decomposed into three additive components following Gauch et al. (2003): the Squared Bias (SB), the Non-Unity slope (NU) and the Lack of Correlation (LC).

$\mathrm{SB}=(\bar{m}-\bar{o})^{2}$

$\mathrm{NU}=\left(1-\frac{\Sigma(m-\bar{m}) \times(o-\bar{o})}{\Sigma(m-\bar{m})^{2}}\right)^{2} \times \frac{\Sigma(m-\bar{m})^{2}}{n}$
$\mathrm{LC}=\left(1-\frac{\Sigma((m-\bar{m}) \times(o-\bar{o}))^{2}}{\Sigma(o-\bar{o})^{2} \times \Sigma(m-\bar{m})^{2}}\right) \times \frac{\Sigma(o-\bar{o})^{2}}{n}$

SB provides information about the mean bias of the simulation from the measurement. NU indicates the capacities of the model to reproduce the magnitude of fluctuation among the measurements. It can be considered as an indicator of the model's capacities to reproduce the scatttering of the data. LC is an indication of the dispersion of the point over a scatterplot, i.e., the capacities of the model to reproduce the shape of the data.

Even though the previous statistical indicators are useful to compare one model with the data, they must be not used to compare the models together because they do not consider the differences in the parameters number. In order to do so, we used the Bayesian Information Criterion (BIC).

$\mathrm{BIC}=\log (\mathrm{MSD}) \times n+\log (n) \times p$

where MSD is the mean squared deviation calculated with Eq. (16), $n$ the number of samples (i.e., 12 in our case, one per profile), and $p$ the number of parameters.

\section{Results}

The optimised parameters and their associated variances are presented in the Tables 1 and 2. For some models, important correlation factors were observed (supplemental material Fig. 1). Considering the method used to optimise the parameters, these important correlation factors make complicated the presentation of the model output within an envelope. Therefore, we presented the model results using the optimised parameter without any envelope (Figs. 4, 5 and 6). The most important correlations were generally observed between $\mu$ and $k_{\text {SOM }}$ which control the input and the output of 
Table 3. Bayesian Information Criterion (BIC).

\begin{tabular}{lrrrrrrr}
\hline & MIN1- $T_{\mathrm{A}}$ & MIN1- $T_{\mathrm{D}}$ & MIN1- $T_{\mathrm{AD}}$ & MIN2- $T_{\mathrm{A}}$ & MIN2- $T_{\mathrm{D}}$ & MIN2- $T_{\mathrm{AD}}$ & MIN3- $T_{\mathrm{AD}}$ \\
\hline Entire dataset & 181.4 & 179.3 & 173.6 & 196.2 & 182.1 & 177.7 & 200.5 \\
Steppe & 63.3 & 39.2 & 57.0 & 67.2 & 59.5 & 61.6 & 70.7 \\
20 yr bare fallow & 41.2 & 51.7 & 46.3 & 54.1 & 45.8 & 40.8 & 56.5 \\
26 yr bare fallow & 48.4 & 56.5 & 50.6 & 57.6 & 50.0 & 47.4 & 53.3 \\
58 yr bare fallow & 54.1 & 59.8 & 58.4 & 54.6 & 62.3 & 63.3 & 70.8 \\
\hline
\end{tabular}
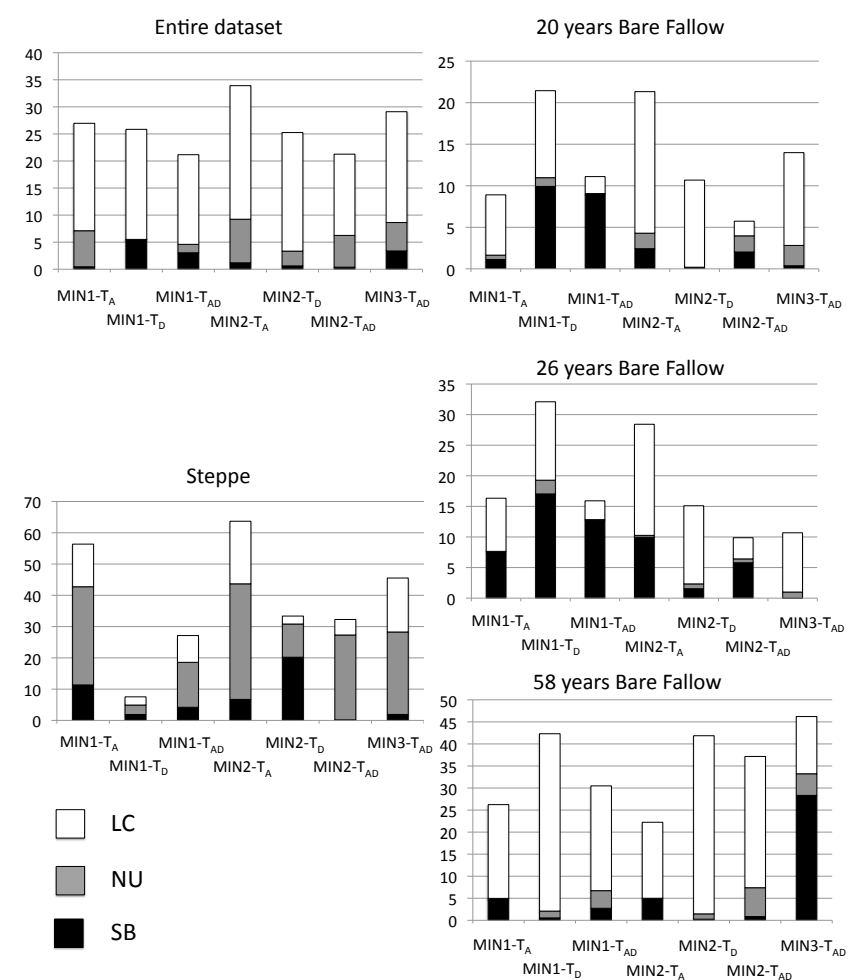

Fig. 3. Components of mean squared deviation (MSD) for the seven formulations. The lowest the MSD value is, the best the fit is. The three components are lack of correlation (LC), non-unity slope (NU), and squared bias (SB).

the SOM pools, but also between $c$ and $k_{\mathrm{SOM}}$ for MIN2- $T_{\mathrm{D}}$ which both control the SOM mineralisation.

\subsection{The representation of SOM decomposition}

Figure 3 describes the MSD, SB, NU and LC statistical indicator values obtained by each different model for the entire dataset, or for each site. When MSD was calculated for the entire dataset, we observed generally very closed values of MSD between MIN1 and MIN2 except for $T_{\mathrm{A}}$ formulation where the use of a first order kinetic to describe SOM mineralisation improve the fit with the data. With BIC that takes into account the effect of the parameter increase on the fit, the same pattern was observed (Table 3). The MIN3- $T_{\mathrm{AD}}$ model presents a high MSD value. Even though, MSD val- ues are close for $T_{\mathrm{D}}$ and $T_{\mathrm{AD}}$ formulation, the values of the MSD components are different. MIN2 (priming model) decrease the SB values indicating that this formulation better represents the mean $\mathrm{C}$ stock over the profile, whereas MIN1 decrease the NU values, suggesting that first order kinetics better represent the data scattering.

For the youngest bare fallow plots, we always observed the same patterns. MSD values are reduced using priming model (MIN2) when soil $\mathrm{C}$ transport is represented using advection $\left(T_{\mathrm{A}}\right)$ and both advection and diffusion $\left(T_{\mathrm{AD}}\right)$. The BIC is following the same pattern (Table 3). In these cases, the improvement is mainly due to an important reduction of the SB values indicating the priming model (MIN2) better represent the mean $\mathrm{C}$ stock over the profile. Indeed, the Figs. 4 and 5 show that the MIN1 formulation overestimates the decomposition. However, when transport was represented using only advection $\left(\mathrm{T}_{A}\right)$ the priming model (MIN2) over estimated the decomposition in the surface layers. The MIN3 formulation (three $\mathrm{C}$ pools) never presented the lowest MSD values when both advection and diffusion were represented. However, the SB value was reduced when SOM decomposition was described using MIN3.

For the oldest bare fallow, the priming model (MIN2) reduced MSD values when $\mathrm{C}$ transport was described using advection only $\left(T_{\mathrm{A}}\right)$ or diffusion only $\left(T_{\mathrm{D}}\right)$. When C transport mechanism was only advection, priming model (MIN2) reduced the $\mathrm{LC}$ value but increased the SB value indicating that MIN2 better reproduced the shape of the data, but poorly represented the mean $\mathrm{C}$ stock over the profile. For $T_{\mathrm{D}}$ formulation, the priming model (MIN2) better represented the mean C stock over the profile (reduced SB values) and the data scattering (reduced NU values). However, the lowest BIC values were always obtained with MIN1 whatever the $\mathrm{C}$ transport mechanisms used (Table 3). The highest MSD value was obtained with the MIN3 formulation for the oldest bare fallow, but LC value was largely reduced indicating that such formulation better represented the shape of the data.

For the steppe profile, the priming model (MIN2) increased the MSD and the BIC values for the three transport mechanisms. In particular, when only diffusion was represented $\left(T_{\mathrm{D}}\right)$ the MIN2 formulation overestimated the $\mathrm{C}$ stock (Figs. 4 and 5). The MIN3 formulation never improved the description of the steppe profile. 


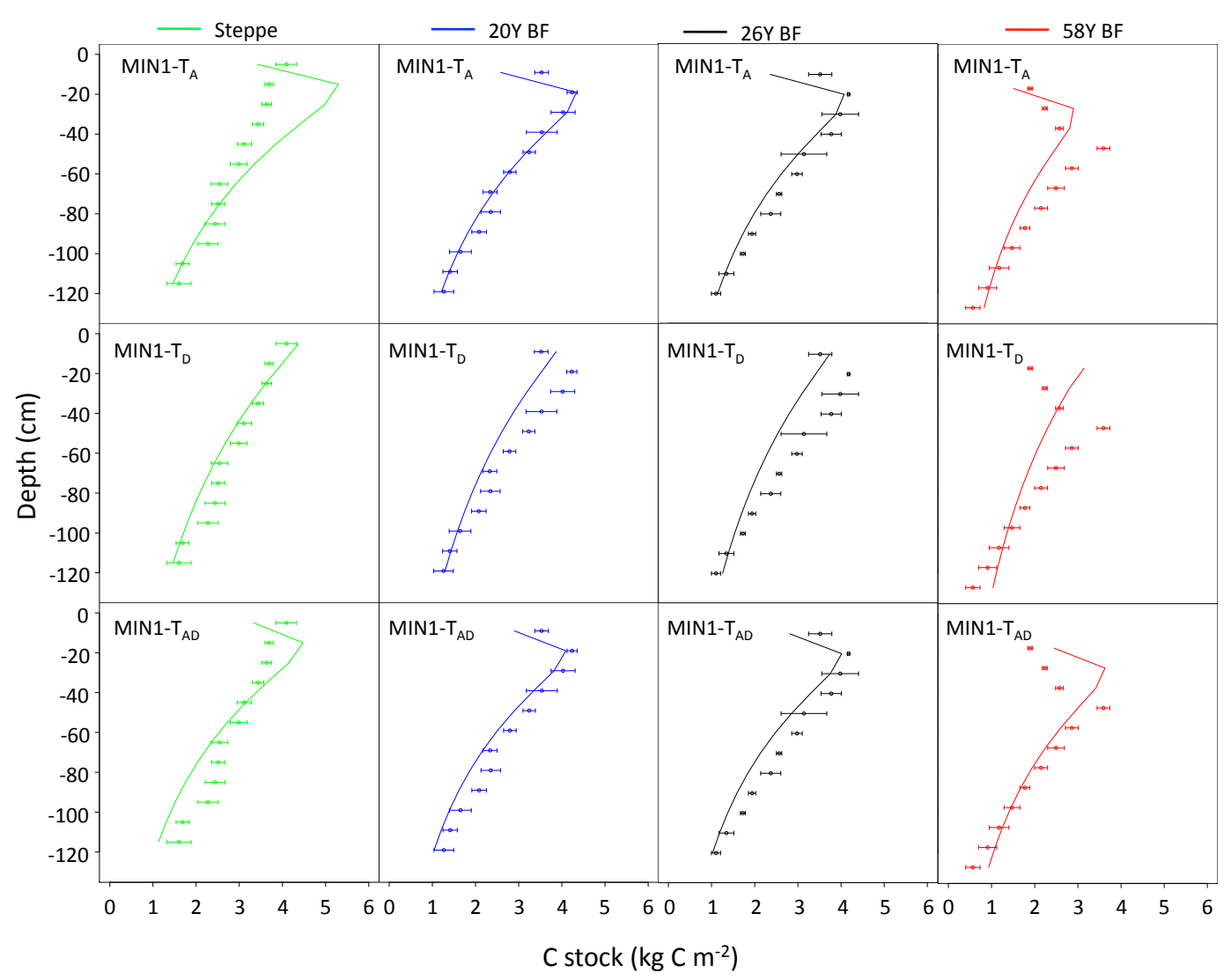

Fig. 4. Total Organic Carbon for the MIN1 transport scheme (first order kinetics) and the three transport schemes $\left(T_{\mathrm{A}}, T_{\mathrm{D}}, T_{\mathrm{AD}}\right)$. Measured $\mathrm{C}$ stocks are represented by the circles and modelled $\mathrm{C}$ stocks by the lines.

\subsection{The transport formulation}

Considering the entire dataset, for each SOM mineralisation formulation, the best fit was always obtained with the same transport formulation $\left(T_{\mathrm{AD}}\right)$. This was also the case for the $58 \mathrm{YBF}$, but for this profile, the best fit was always obtained with advection only. It is interesting to note that for the steppe and the youngest bare fallows (20YBF and $26 \mathrm{YBF}$ ), the transport mechanisms that reduce the MSD and the BIC values depended on the SOM mineralisation formulation used. When using the MIN2 substrates interactions representation, the best fits were obtained with the formalisms including advection and diffusion (Fig. 3). In this case, for the steppe, the SB values were particularly reduced. However, the lowest BIC values were obtained when only diffusion is represented. For the 20YBF, it was the LC value that was reduced, suggesting that the shape of the curves is better represented with advection and diffusion. When using MIN1, the best fit for the steppe was obtained using only diffusion. The scattering of the data was better represented in this case (reduced NU values). For the $20 \mathrm{YBF}$, the best fit was obtained using advection only $\left(T_{\mathrm{A}}\right)$. Here, the $\mathrm{SB}$ values were largely reduced. It is interesting to note that the mechanisms transport that produced the best fit with the data changed depending on the FOM availability. Indeed, when SOM mineralisation was represented by MIN1, the best fit was obtained with diffusion $\left(T_{\mathrm{D}}\right)$ for the steppe and then with advection $\left(T_{\mathrm{A}}\right)$ for the bare fallows. With the priming model (MIN2), the lowest BIC values were always obtained with only diffusion for the steppe, then with both advection and diffusion $\left(T_{\mathrm{AD}}\right)$ for $20 \mathrm{YBF}$ and 26YBF. Finally, for the 58YBF only advection was needed to fit the data.

\section{Discussion}

\subsection{The representation of SOM decomposition}

Our goal was to better separate the role of vertical transport mechanisms such as diffusion/advection given different formulation of SOM decomposition using a simple conceptual model of SOM decomposition. For the data we used, we first showed that the substrates interactions representation proposed by Wutlzer and Reichstein (2008) was an interesting formulation to represent cases where FOM is not at the equilibrium such as in the young bare fallow soil (20YBF and $26 \mathrm{YBF}$ ). For the entire set of cases, the priming model reduced the standard bias and, therefore, better reproduced the 


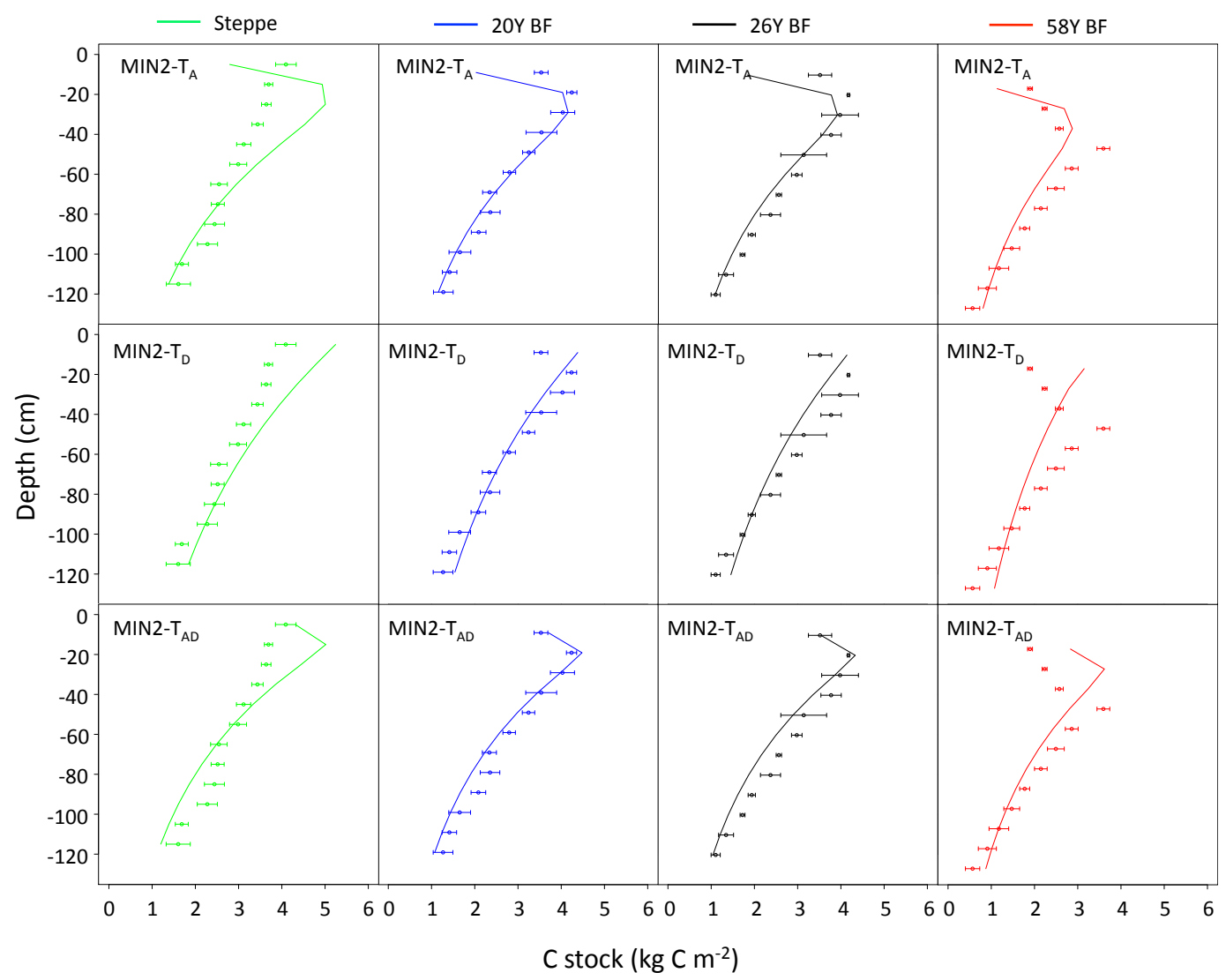

Fig. 5. Total Organic Carbon for the MIN2 transport scheme (priming model) and the three transport schemes $\left(T_{\mathrm{A}}, T_{\mathrm{D}}, T_{\mathrm{AD}}\right) . \mathrm{Measured}_{\mathrm{C}}$ stocks are represented by the circles and modelled $\mathrm{C}$ stocks by the lines.

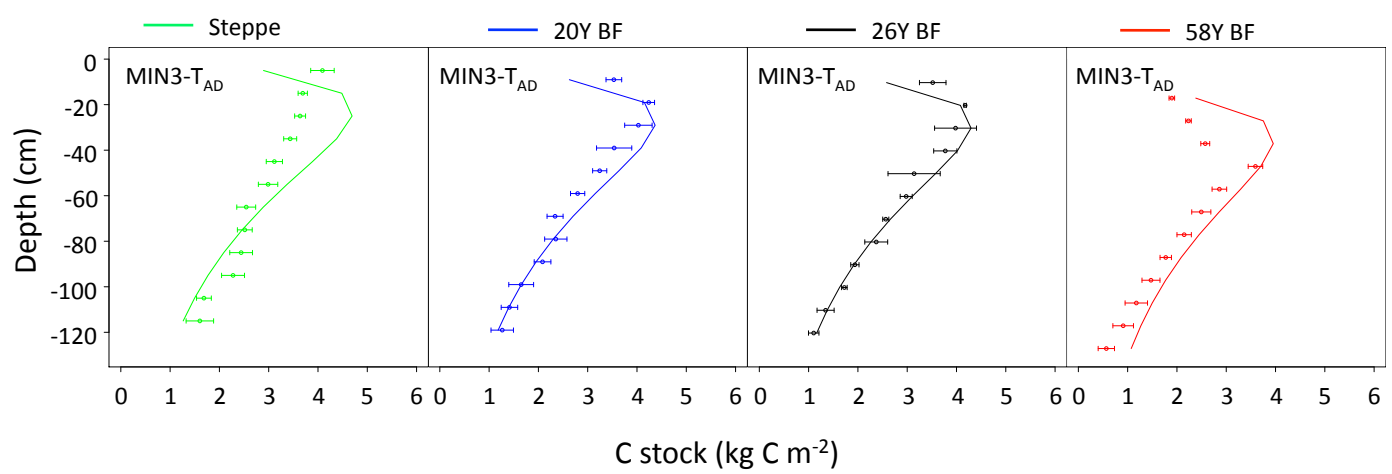

Fig. 6. Total Organic Carbon for the MIN3 transport scheme (three pools model) and the $T_{\mathrm{AD}}$ transport schemes. Measured C stocks are represented by the circles and modelled $\mathrm{C}$ stocks by the lines.

mean $\mathrm{C}$ stock over the profile. For the youngest bare fallow, the priming formulation better performed when $T_{\mathrm{D}}$ or $T_{\mathrm{AD}}$ transport formulation are used. For the steppe, where the FOM stock is at equilibrium, the MIN1 better performed for the three transport mechanisms. However, the priming model improved the model output for the deep layers $(>40 \mathrm{~cm})$ where FOM amount was low (Fig. 6). For the youngest bare fallow (20YBF), the profile representation was improved for the priming model when advection and both advection and diffusion were represented. Indeed, when SOM decomposition was described by first order kinetics the model overestimated the SOM decomposition in deep soil layers. This result is in agreement with the study of Dörr and Münnich (1989). It suggests that the SOM decomposer activity is largely controlled by the availability of FOM at the Kursk site, and that using a single decomposition rate for all the soil layers 


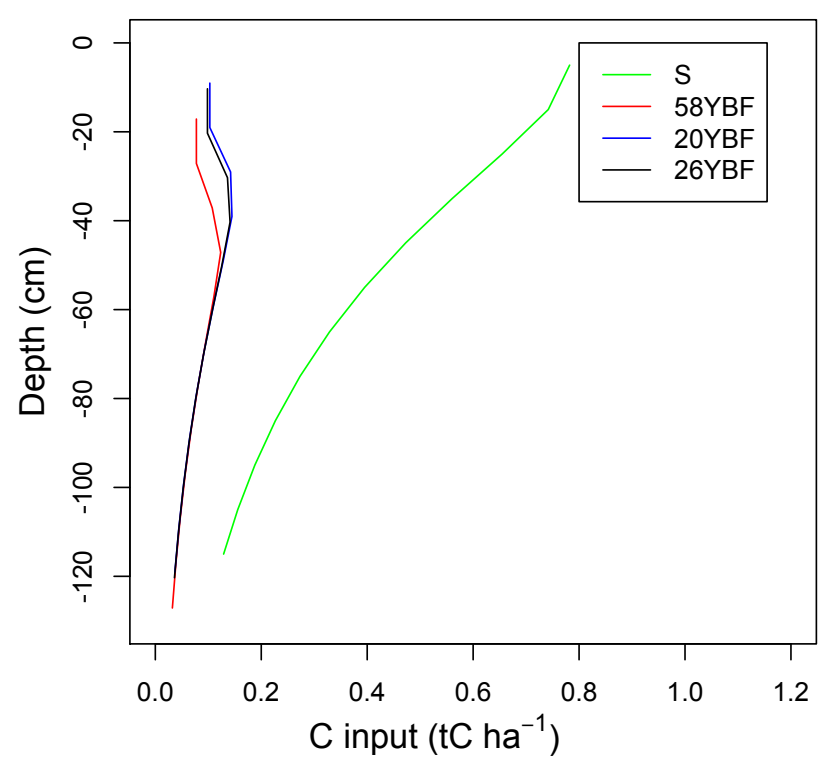

Fig. 7. Fresh organic matter for the four profiles calculated by the model. The steppe, the $20 \mathrm{YBF}$, the $26 \mathrm{YBF}$ and the $58 \mathrm{YBF}$ are represented by the green line, the blue line, the black line and the red line, respectively. All the models share the same input scheme. We assume that in the models a fraction of the SOM decomposed may be as labile as the FOM and is, therefore, incorporated to the FOM pool.

parameterised on the top layers might lead to largely overestimate SOM decomposition at depth (and underestimate it near the surface). This conclusion is in agreement with the results of Fontaine et al. (2007) who observed an important increase of SOM mineralisation at depth when FOM was added in an in vitro experiment. Finally, the MIN3 formulation never obtained the lowest BIC, suggesting that the best fit is not always obtained with the most parameterised model. It shows that when the priming model improves the fit with the data, it is not just an effect of increasing the number of parameters.

\subsection{Transport mechanisms}

We found that for the MIN1 formulation the worst fit to the data was always observed when only diffusion was represented, except for the steppe. In particular, the LC values were higher indicating that the shape of the data curves was not well represented when using only diffusion. When the MIN2 (priming model) was used, the worst fit was always obtained with advection except for 58YBF. In this case, the LC values are high, indicating that using advection only was not sufficient to reproduce the shape of the profile. The advection rates obtained after optimisation in this study were ten times higher than those presented in Bruun et al. (2007), but ten times lower than those presented in Braakhekke et al. (2011). For the diffusion coefficient, the values obtained here after optimisation are also higher than those of Bruun et al. (2007) (one or two range of magnitude), but this diffusion coefficient is a function of the bulk density (Braakhekke et al., 2011). Thus, differences in the bulk density between the soil used here and the one used by Bruun et al. (2007) might explain the different diffusion coefficients. Baisden et al. (2002) obtained good agreement between data and model output with a model which only uses advection as transport mechanism. The advection rates in our study are in agreement with those observed by Baisden et al. (2002).

When substrates interactions are included in any of the conceptual models, we observed that only diffusion must be represented to properly fit the data for the steppe where FOM is available. Then, for $20 \mathrm{YBF}$ and $26 \mathrm{YBF}$ profiles, a representation of diffusion and advection was needed to fit well with the data. Finally, for the 58YBF profile, only advection was needed. A shift from diffusion to advection, as the most important mechanism to fit the data, was also observed when SOM mineralisation was described by first order kinetics. However, in this case advection was already the most important mechanism for $20 \mathrm{YBF}$ and $26 \mathrm{YBF}$ soils. In long-term bare fallows older than $40 \mathrm{yr}$, most of the labile $\mathrm{C}$ has been mineralised (Barré et al., 2010). Consequently, the SOM in this soil is quite different in decomposability from that in the youngest bare fallow plots and from the steppe. For example, particulate organic matter, i.e., decomposing plant residues, which are labile components of SOM are depleted from a temperate bare fallow in a few decades (Vasilyeva et al., 2013). Diffusion is often used to account for transport of plant debris and particulate organic matter by soil fauna, whereas advection is used to represent $\mathrm{C}$ transport with the liquid phase (O'Brien and Stout, 1978; Wynn et al., 2005; Braakhekke et al., 2011). Soil fauna activity is closely related to SOM availability (Decaëns, 2010). Therefore, the importance of soil fauna in the transport $\mathrm{C}$ in our sites decreased when FOM input were stopped and, therefore, when SOM availability was reduced. This suggests that different pools of SOM could be transported through different mechanisms. The more labile OM may be transported mainly by bioturbation, whereas the more stabilised may be transported with the liquid phase. To our knowledge, this is the first time that different transport mechanisms are suggested for different pools of $\mathrm{C}$. This assumption must be tested against other soil profiles from bare fallow experiments, but if confirmed it suggests that soil models using different pools of $\mathrm{C}$ and aiming to represent the $\mathrm{C}$ distribution within a profile must use different transport mechanisms for labile and stable pools.

\subsection{Transport mechanisms depending on the SOM decomposition formulation}

We observed that the transport mechanism inducing the best fit for youngest bare fallow (20YBF and 26YBF) where FOM stock are out from equilibrium was not always the same for each decomposition formulation and might, 
therefore, depend on the formulation used to described SOM decomposition. Indeed, when SOM decomposition was described with a first order kinetic, the best fit could only be obtained with advection as the sole transport mechanism. However, a better fit was obtained with both advection and diffusion as transport mechanisms when SOM decomposition depended on the FOM stock. This suggests that the FOM input regime may determine the most important transport mechanism. Moreover, the structural importance of transport mechanisms in a model depends on how the SOM decomposition is formulated. As a consequence, the use of such models to understand and separate mechanisms not directly observable may be a highly complex task, whose results could depend on the underlying assumption in the formulation of the SOM decomposition. For example, a first order kinetic model such as the one used in this study assumes that the microbial community responsible for SOM decomposition is stable in terms of biomass, but also in terms of structure and physiology during the period considered. Several observations showed that microbial community structure, biomass and physiology are controlled by environmental conditions such as soil moisture (e.g., Williams, 2007; Guenet et al., 2011) or temperature (e.g., Pettersson and Bååth, 2003; Wu et al., 2009). Moreover, Hirsch et al. (2009) showed that the microbial community structure differ between grassland and bare fallow soils. The absence of an explicit representation of the microbial community or biomass might explain also why our models do not fit so well with the data when first order kinetics are used. The second formulation obtained generally better fits, but was not able to reproduce all the profiles perfectly. The latter assumes that there is a constant nutrient limitation on the microbial activity, which is implicitly represented in the parameters of the model. Mikhailova et al. (2000) showed that the $\mathrm{N}$ profiles in the Kursk site also differ between bare fallow and the control. Thus, an explicit representation of the $\mathrm{N}$ cycle in the profile might decrease the MSD values. Finally, the effects of temperature and soil moisture are not represented in the models because not enough climate data was available. The absence of such effects may explained at least partially why the models and, in particular, the most complex do not perfectly fit with the data after optimisation.

To our knowledge, this is the first time that the importance of SOM decomposition formulation on the transport formulation is analysed and showed and it could have important consequences on the representation of $\mathrm{C}$ transport in the model. Indeed, developing models inclusive of more and more mechanisms should likely improve our capacities to reproduce large scales datasets and improve our understanding of the $\mathrm{C}$ cycle in the soil. Nevertheless, one must keep in mind that these mechanisms will interact with each other within the model structure and the choice of a certain representation of different mechanisms will depend on how others mechanisms are represented in the model.

\subsection{Does a model perform better?}

Regarding the MSD values for the entire dataset, we may conclude that the better model over the six models tested would be the MIN1- $T_{\mathrm{AD}}$ and the MIN2- $T_{\mathrm{AD}}$ which presented very close values of MSD. However, the MIN2- $T_{\mathrm{AD}}$ had one more parameter and BIC must be used instead of MSD to take into account the differences in the parameter number. Using BIC MIN1- $T_{\mathrm{AD}}$ would be the best model. Nevertheless, when each profile is analysed independently, MIN2- $T_{\mathrm{AD}}$ obtained the lowest BIC values for half of the profile. The answer may also depend on the objectives fixed for the study. Using the Gauch et al. (2003) evaluation methods, we evaluated different characteristics of the models such as their capacities to reproduce the mean $\mathrm{C}$ stock value over the profile, the standard deviation around this mean value and the shape of the profile. For example, if the objective is to represent the data scattering of the steppe profile very well, we should use the model MIN1- $T_{\mathrm{D}}$. But if the objective is to evaluate the mean $\mathrm{C}$ stock of the steppe, we should use the model MIN2- $T_{\mathrm{AD}}$. Furthermore, the LC values were generally the highest contributor to MSD. It suggests that all models were not very good to precisely reproduce the shape of the data. Finally, the correlation matrix (Supplement Fig. 1) showed some cases with important correlations between parameters, making it difficult for the calculation of an envelope. However, generally, correlation factors were low indicating that our model was not over-parameterised in spite of the limited amount of data compared to the number of optimised parameters.

\section{Supplementary material related to this article is available online at: http://www.biogeosciences.net/10/ 2379/2013/bg-10-2379-2013-supplement.pdf.}

Acknowledgements. The authors acknowledge the reserve staff for maintaining such an experimental site for so long and for the access to the data. The authors thank the GIS-Climat Environnement Société program CARBOSOIL and R2DS for financial support.

Edited by: E. Veldkamp

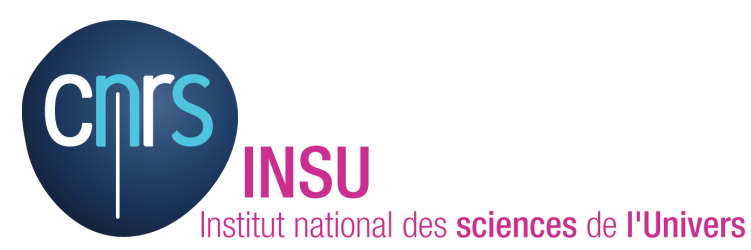

The publication of this article is financed by CNRS-INSU. 


\section{References}

Afanasyeva, E. A.: Chernozemy sredne-russkoi vozvishennosti, Nauka, Moscow, 224 pp., 1966 (in Russian).

Baisden, W. T.: A multiisotope $\mathrm{C}$ and $\mathrm{N}$ modeling analysis of soil organic matter turnover and transport as a function of soil depth in a California annual grassland soil chronosequence, Global Biogeochem. Cy., 16, 1135, doi:10.1029/2001GB001823, 2002.

Barré, P., Eglin, T., Christensen, B. T., Ciais, P., Houot, S., Kätterer, T., van Oort, F., Peylin, P., Poulton, P. R., Romanenkov, V., and Chenu, C.: Quantifying and isolating stable soil organic carbon using long-term bare fallow experiments, Biogeosciences, 7, 3839-3850, doi:10.5194/bg-7-3839-2010, 2010.

Batjes, N. H.: Total carbon and nitrogen in the soils of the world, Eur. J. Soil Sci., 47, 151-163, 1996.

Braakhekke, M. C., Beer, C., Hoosbeek, M. R., Reichstein, M., Kruijt, B., Schrumpf, M., and Kabat, P.: SOMPROF: A vertically explicit soil organic matter model, Ecol. Model., 222, 17121730, 2011.

Bruun, S., Christensen, B. T., Thomsen, I. K., Jensen, E. S., and Jensen, L. S.: Modeling vertical movement of organic matter in a soil incubated for 41 years with ${ }^{14} \mathrm{C}$ labeled straw, Soil Biol. Biochem., 39, 368-371, 2007.

Coleman, K., Jenkinson, D. S., Crocker, G. J., Grace, P. R., Klir, J., Körschens, M., Poulton, P. R., and Richter, D. D.: Simulating trends in soil organic carbon in long-term experiments using RothC-26.3., Geoderma, 81, 29-44, 1997.

Decaëns, T.: Macroecological patterns in soil communities, Glob. Ecol. Biogeogr., 19, 287-302, 2010.

Dörr, H. and Münnich, K.: Downward movement of soil organic matter and its influence on trace element transport, Radiocarbon, 31, 655-663, 1989.

Elzein, A. and Balesdent, J.: Mechanistic Simulation of VerticalDistribution of Carbon Concentrations and Residence Times in Soils, Soil Sci. Soc. Am. J., 59, 1328-1335, 1995.

Feng, X., Peterson, J. C., Quideau, S. A., Virginia, R. A., Graham, R. C., Sonder, L. J., and Chadwick, O. A.: Distribution, accumulation, and fluxes of soil carbon in four monoculture lysimeters at San Dimas Experimental Forest, California, Geochim. Cosmochim. Ac., 63, 1319-1333, 1999.

Fontaine, S. and Barot, S.: Size and functional diversity of microbe populations control plant persistence and long-term soil carbon accumulation, Ecol. Lett., 8, 1075-1087, 2005.

Fontaine, S., Barot, S., Barré, P., Bdioui, N., Mary, B., and Rumpel, C.: Stability of organic carbon in deep soil layers controlled by fresh carbon supply, Nature, 450, 277-280, 2007.

Friedlingstein, P., Cox, P., Betts, R., Bopp, L., Von Bloh, W., Brovkin, V., Cadule, P., Doney, S., Eby, M., Fung, I., Bala, G., John, J., Jones, C., Joos, F., Kato, T., Kawamiya, M., Knorr, W., Lindsay, K., Matthews, H. D., Raddatz, T., Rayner, P., Reick, C., Roeckner, E., Schnitzler, K. G., Schnur, R., Strassmann, K., Weaver, A. J., Yoshikawa, C., and Zeng, N.: Climate-carbon cycle feedback analysis: Results from the C4MIP model intercomparison, J. Climate 19, 3337-3353, 2006.

Gauch Jr., H. G., Hwang, J. T., and Fick, G. W.: Model Evaluation by Comparison of Model-Based Predictions and Measured Values, Agron. J., 95, 1442-1446, 2003.

Guenet, B., Lenhart, K., Leloup, J., Giusti-Miller, S., Pouteau, V., Mora, P., Nunan, N., and Abbadie, L.: The impact of long-term $\mathrm{CO}_{2}$ enrichment and moisture levels on soil microbial commu- nity structure and enzyme activities, Geoderma, 170, 331-336, 2011.

Hirsch, P. R., Gilliam, L. M., Sohi, S. P., Williams, J. K., Clark, I. M., and Murray, P. J.: Starving the soil of plant input for 50 years reduces abundance but not diversity of soil bacterial communities, Soil Biol. Biochem., 41, 2021-2024, 2009.

Jenkinson, D. S. and Coleman, K.: The turnover of organic carbon in subsoils. Part 2. Modelling carbon turnover, Eur. J. Soil Sci., 59, 400-413, 2008.

Jobbagy, E. G. and Jackson, R. B.: The vertical distribution of soil organic carbon and its relation to climate and vegetation, Ecol. Appl., 10, 423-436, 2000.

Kobayashi, K. S. and Salam, M. U.: Comparing simulated and measured values using mean squared deviation and its components. Agron. J., 92, 345-352, 2000.

Lueken H., Hutcheon, W. L., and Paul, E. A.: The influence of nitrogen on the decomposition of crop residues in soil, Can. J. of Soil Sci., 42, 276-288, 1962.

Manzoni, S. and Porporato, A.: Soil carbon and nitrogen mineralisation: Theory and models across scales, Soil Biol. Biochem., 41, 1355-1379, 2009.

MEA: Millennium Ecosystem Assessment-Nutrient Cycling, World Resource Institute, Washington DC, 2005.

Mikhailova, E. A., Vassenev, R. B., Schwager, I. I., and Post, S. J.: Cultivation effects on soil carbon and nitrogen contents at depth in the Russian Chernozem, Soil Sci. Soc. Am. J., 64, 738-745, 2000

O'Brien, B. J. and Stout, J. D.: Movement and turnover of soil organic matter as indicated by carbon isotope measurements, Soil Biol. Biochem., 10, 309-317, 1977.

Parton, W. J., Stewart, J. W. B., and Cole, C. V.: Dynamics of C, N, $\mathrm{P}$ and $\mathrm{S}$ in grassland soils - a model, Biogeochemistry, 5, 109131, 1988.

Pettersson, M. and Bååth, E.: Temperature-dependent changes in the soil bacterial community in limed and unlimed soil, FEMS Microbiol. Ecol., 45, 13-21, 2003.

R Development Core Team: A language and environment for statistical computing, R Foundation for Statistical Computing, Vienna, Austria, ISBN 3-900051-07-0, http://www.R-project.org., 2010.

Rumpel, C. and Kögel-Knabner, I.: Deep soil organic matter - a key but poorly understood component of terrestrial C cycle, Plant Soil, 338, 143-158, 2010.

Salomé, C., Nunan, N., Pouteau, V., Lerch, T. Z., and Chenu, C.: Carbon dynamics in topsoil and in subsoil may be controlled by different regulatory mechanisms, Glob. Change Biol., 16, 416426, 2010.

Sanaullah, M., Chabbi, A., Leifeld, J., Bardoux, G., Billou, D., and Rumpel, C.: Decomposition and stabilization of root litter in topand subsoil horizons: what is the difference?, Plant Soil, 338, 127-141, 2010.

Santaren, D., Peylin, P., Viovy, N., and Ciais, P.: Optimizing a process-based ecosystem model with eddy-covariance flux measurements: A pine forest in southern France, Global Biogeochem. Cy., 21, GB2013, doi:10.1029/2006GB002834, 2007.

Schimel, D. S.: Terrestrial ecosystems and the carbon cycle, Glob. Change Biol., 1, 77-91, 1995.

Schlesinger, H. W.: Evidence from chronosequence studies for a low carbon-storage potential of soils, Nature, 348, 232-234, 1990. 
Soetaert, K., Petzoldt, T., and Setzer, R. W.: Solving Differential Equations in R: Package deSolve, J. Stat. Softw., 33, 1-25, 2010.

Sparling, G. S., Cheschire, M. V., and Mundie, C. M.: Effect of barley plants on the decomposition of 14C-labelled soil organic matter, J. Soil Sci., 33, 89-100, 1982.

Sugden, A., Stone, R., and Ash, C.: Ecology in the underworld Introduction, Science, 304, 1613-1613, 2004.

Tarantola, A.: Inverse Problem Theory: Methods of Data Fitting and Model Parameter Estimation, Elsevier Science Ltd., 630 pp., 1987.

Tarnocai, C., Canadell, J. G., Schuur, E. A. G., Kuhry, P., Mazhitova, G., and Zimov, S.: Soil organic carbon pools in the northern circum-polar permafrost region, Global Biogeochem. Cy., 23, GB2023, doi:10.1029/2008GB003327, 2009.

Vasilyeva, N. A., Chenu, C., Tyugai, Z. N., and Milanovskiy, E. Y.: Century scale $\mathrm{C}$ metastability in full Chernozem profiles under changed organic matter input and tillage, in press, 2013.

Vinogradov, B. V.: Aerospace studies of protected natural areas in the USSR, in: Conservation, science and society, Nat. Resour. Res., XXI, Vol. 2, 435-448, UNESCO-UNEP, Paris, 1984.
Williams, M.: Response of microbial communities to water stress in irrigated and drought-prone tallgrass prairie soils, Soil Biol. Biochem., 39, 2750-2757, 2007.

Wu, J., Brookes, P. C., and Jenkinson, D. S.: Formation and destruction of microbial biomass during the decomposition of glucose and Ryegrass in Soil, Soil Biol. Biochem., 25, 1435-1441, 1993.

Wu, Y., Xiongsheng, Y., Haizhen, W., Na, D., and Jianming, $\mathrm{X}$.: Does history matter? Temperature effects on soil microbial biomass and community structure based on the phospholipid fatty acid (PLFA) analysis, J. Soil Sediment, 10, 223-230, 2009.

Wutzler, T. and Reichstein, M.: Colimitation of decomposition by substrate and decomposers - a comparison of model formulations, Biogeosciences, 5, 749-759, doi:10.5194/bg-5-749-2008, 2008.

Wynn, J. G., Bird, M. I., and Wong, V. N. L.: Rayleigh distillation and the depth profile of $13 \mathrm{C} / 12 \mathrm{C}$ ratios of soil organic carbon from soils of disparate texture in Iron Range National Park, Far North Queensland, Australia, Geochim. Cosmochim. Ac., 69, 1961-1973, 2005.

Zhu, C., Byrd, R. H., Lu, P., and Nocedal, J.: A limited memory algorithm for bound constrained optimisation, SIAM J. Sci. Stat. Comput., 16, 1190-1208, 1995. 